\title{
O dualismo pulsional e suas exigências
}

\section{The driving dualism and its demands}

\section{Oswaldo Giacoia Júnior}

Resumo: O principal objetivo do presente trabalho consiste em explicitar como a exigência de manter o dualismo das pulsões na metapsicologia de Freud vincula-se estreitamente ao conceito de pulsão como elasticidade orgânica ou como a expressão da inércia da vida orgânica.

Palavras-chave: Metapsicologia; Pulsões; Dualismo; Libido; Destrutividade; Compulsão à Repetição; Princípio de Nirvana; Princípio do Prazer

Abstract: The main objective of this paper is to explain how the requirement to maintain the dualism of drives in Freud's metapsychology is closely linked to the concept of drive as organic elasticity or as the expression of the inertia of organic life.

Keywords: Metapsychology; Drives; Dualism; Libido; Destructiveness; Compulsion to Repeat; Nirvana principle; Pleasure principle

Na abertura do Projeto de uma Psicologia (1885), Freud deixa patente o que considera a condição preliminar e inarredável de uma Psicologia científica:

O propósito deste projeto é fornecer uma Psicologia como ciência natural, isto é, apresentar os processos (Vorgänge) psíquicos como estados (Zustände) quantitativamente determinados de componentes materiais exibíveis, e com isso torná-los intuitivamente perceptíveis (anschaulich) e livres de contradição. O projeto contém duas ideias principais: 1) conceber como quantidade $(\mathrm{Q})$ submetida à lei universal do movimento aquilo que diferencia atividade de repouso; 2) admitir os neurônios como partículas materiais ${ }^{1}$.

Sabemos que pelo menos desde A Interpretação dos Sonhos o acento marcadamente fisiológico dos primeiros textos metapsicológicos de Freud sofreu considerável modificação, resultado de uma inflexão teórica que determinou os rumos futuros da Psicanálise no campo da Psicologia. No entanto, as ideias que estavam em elaboração no Projeto de uma Psicologia e outros textos contemporâneos deste esboço não foram

\footnotetext{
${ }^{1}$ FREUD, Entwurf einer Psychologie, p. 305
}

* Professor Titular do Departamento de Filosofia da Universidade Estadual de Campinas, Campinas, SP. E-mail: ogiacoia@hotmail.com ORCID: https://orcid.org/0000-0002-3064-8583 
simplesmente abandonadas por Freud, desacreditadas como impertinentes ao trabalho em curso, senão que permaneceram atuantes nos bastidores da teorização metapsicológica.

Com frequência, elas retornam reformuladas à superfície dos textos, entremeadas com noções, conceitos, perspectivas e novas aquisições, com auxílio das quais o pensamento teórico é convocado a atender as dificuldades nascidas da prática clínica, ou mesmo às necessidades de reelaboração da própria teoria. O que é certo, no entanto, é que Freud nunca amenizou a obrigação de que a teoria fosse posta a serviço das vicissitudes e dificuldades da prática clínica, mantendo-se a especulação nos limites fixados pelos parâmetros reconhecidos e praticados pelas ciências da natureza de seu tempo. Mas Freud nunca recuou diante das exigências de amplo fôlego especulativo, quando para tanto fosse instado por necessidades internas do corpus teórico psicanalítico.

Um exemplo marcante dessa vicissitude pode ser encontrado em Além do Princípio do Prazer, no qual as dificuldades oriundas da observação metódica de fenômenos clínicos compelem Freud à ousadia de aventurar-se no tormentoso oceano da metafísica. Também neste caso, são os fenômenos à primeira vista inexplicáveis da repetição coercitiva de experiências negativas - sem perspectiva de ganho de prazer e evitação de sofrimento - que dão ensejo e mobilizam os primeiros passos da especulação metapsicológica.

É a reflexão sobre as experiências aflitivas vivenciadas nas brincadeiras infantis, nos sonhos de pacientes acometidos por neuroses traumáticas, nos processos transferenciais vivenciados no set analítico, nos sonhos dos pacientes em análise, bem como na desconcertante repetição de destinos, caracterizada como 'eterno retorno do mesmo', que desembocam na formulação da pergunta desconcertante: se o princípio do prazer é o dispositivo que regula e explica o modo funcionamento do aparelho psíquico, então como compreender aqueles fenômenos, nos quais a finalidade visada pelo binômio prazer/desprazer parece ter sido posta inteiramente fora de consideração? Como explicar que grande parte de nossa vida psíquica seja inevitavelmente marcada pelo sofrimento, pelo desprazer não pela satisfação?

Deste impasse, o pensamento é levado para a explicitação de funções, tendências e operações do aparelho psíquico, como as de ligação das excitações nele acorrentes, sempre consideradas como quantidades de energia nervosa, e daí à postulação necessária de uma tarefa ou préstimo fundamental do psiquismo que tem de ser pressuposta como um momento lógica e (fisio)psicologicamente anterior ao primado do princípio do prazer - e se não contraditória com este, pelo menos independente dele. A trajetória empreendida por Freud se desenvolve, pois, dos fenômenos da repetição à ligação das excitações, da ligação novamente à repetição em seu caráter compulsivo, e daí para uma reconsideração da teoria das pulsões, pois o caráter compulsivo das repetições mencionadas é reconhecido como medularmente constitutivo da essência da pulsão.

A compulsão à repetição exibe dois predicados fundamentais: 1) ela é coercitiva, e, nessa qualidade, desconsidera o ganho de prazer/evitação de desprazer. Isto é: são 
repetidas vivências negativas de grande intensidade, marcadas pelo sofrimento; 2) a repetição mostra-se como um mecanismo a serviço da tarefa de ligação das excitações ingressantes no aparelho psíquico, para fins de preparação das condições e dos percursos que levam à eficaz e satisfatória descarga motora. A compulsão à repetição traz à luz, então, a natureza originária da ligação, como tarefa primária do psiquismo, e, portanto, de realização impositiva. Desse modo, repetição e ligação confluem no elemento comum da coerção. Ora, este mesmo movimento de reposição continuada, esse reproduzir-se sempre de novo, para regredir forçosamente a uma condição anterior, é constitutivo da natureza das pulsões, de modo que a tríade formada por pulsão, ligação e repetição encontra sua expressão unitária elemento da regressão compulsória.

Em Além do Princípio do Prazer, a transição de um elemento para o outro, nesse encadeamento do pensamento que estabelece o vínculo entre os processos acima mencionados, é necessariamente precedida por duas considerações de enorme densidade e relevância: a primeira delas diz respeito à opacidade das pulsões. Estas representam no organismo todos os efeitos de força (Kraftwirkungen) provenientes do interior do corpo, e que são transpostas e traduzidas no interior do aparelho psíquico sob a forma de representações, ideias, pensamentos, sentimentos e afetos, sendo elas mesmas o mais importante e o mais obscuro elemento da investigação psicológica².

E, no entanto, para Freud:

[...] nenhum conhecimento teria sido tão importante para a fundamentação de uma correta Psicologia (einer richtigen Psychologie) como uma compreensão (Einsicht) aproximada da natureza comum e das respectivas particularidades das pulsões. Mas em nenhum outro domínio da Psicologia tateia-se tanto no escuro. Cada um erige tantas pulsões ou 'pulsões fundamentais' quantas lhe agrada, e comercia com elas, como os antigos filósofos da natureza gregos com os seus quatro elementos: a água, a terra, o fogo e o $\mathrm{ar}^{3}$.

A segunda consideração concerne a um ineditismo teórico que passa a comandar o desenvolvimento da revisão da teoria pulsional: aquele que consiste na afirmação do caráter regressivo da pulsão, que desautoriza um entendimento de acordo com o qual toda pulsão seria - stricto sensu - erótica, libidinal, isto é, seria uma força impelindo em sentido agregativo, propulsor do desenvolvimento, da complexificação, da promoção e da evolução da vida orgânica. O caráter coativo da repetição tem em comum com a pulsão justamente este elemento coercitivo, atuando em sentido regressivo, da restauração de um estado anterior do organismo.

\footnotetext{
${ }^{2}$ FREUD, Jenseits des Lustprinzips, p. 244

${ }^{3}$ FREUD, Jenseits des Lustprinzips, p. 260
} 
Nos fenômenos de repetição, o psiquismo regressa forçosamente, reproduz e revive um estado anterior da vida do indivíduo, e visa reagir contra a alteração deste estado, que foi forçado a abandonar sob a pressão de forças acorrentes. Ora, de acordo com o entendimento sustentado por Freud, é isso mesmo o que realiza toda pulsão. Portanto, a dificuldade não se limita à constatação de um grupo de pulsões que seriam de natureza distinta das pulsões de vida - atuando na direção contrária à finalidade natural daquelas -, mas ela alcança a totalidade do fenômeno pulsional.

Uma pulsão seria, portanto, um "Drang” (ímpeto) inerente ao organismo vivo para a reprodução de um estado anterior, ao qual este vivente teve de renunciar sob a influência de forças perturbadoras externas, uma espécie de elasticidade orgânica, ou se quisermos, a expressão da inércia na vida orgânica ${ }^{4}$.

À vista desta inversão que transtorna o entendimento do pulsional como energia vital propulsiva, que, ao invés de impelir para diante, como vetor de desenvolvimento evolutivo, mostra-se como potência regressiva, cuja finalidade é repetir um estado anterior de coisas que o vivente foi forçado a abandonar, fica patente também na tarefa de ligação, bem como nos fenômenos da repetição compulsiva, cuja finalidade consiste justamente na preparação da ligação. E se podemos constatar forças em nós que nos impelem a regredir, é porque há pulsões cuja energia e finalidade não se mobilizam segundo um vetor positivo de crescimento, assimilação, promoção e desenvolvimento, mas existem também em nós energias que - parecendo intensificar e incrementar a vida - na verdade atuam coercitivamente como forças operadoras de processos involutivos, regressivos, desassimilatórios, que levam, portanto, ao contrário da vida - isto é, à morte.

Com isso, descerra-se para Freud a possibilidade de percorrer um caminho reflexivo formado por hipóteses metapsicológicas que, partindo dos primórdios das formas mais incipientes de vida orgânica (a vesícula orgânica elementar, os organismos unicelulares), conduz à constituição do psiquismo como um aparelho ou sistema formado por divisão e diferenciação no complexo mais amplo da matéria animada, também denominada por Freud de substância vida e de vida orgânica. De acordo com tais ficções heurísticas, os organismos - e o aparelho psíquico como uma especificação e diferenciação no interior da vida orgânica, resultado de seu processo de complexificação evolutiva - funcionam como um sistema tendo como uma de suas principais funções o processamento e a distribuição das energias existentes em seu interior - energias estas que são quantidades de excitação nervosa de natureza eletroquímica, portanto grandezas materiais, provenientes tantos de fontes internas (excitações endógenas), quanto externas (estímulos exógenos) -.

Tais quanta de excitação - representantes psíquicos de energias nervosas provenientes de processos intracelulares desenrolando-se interior do corpo, ou de

${ }^{4}$ FREUD, Jenseits des Lustprinzips, p. 247 
estímulos originados da relação entre o organismo e seu meio ambiente natural - devem ser mantidos num nível estável, de modo que cada nova carga de ocupação ou investimento energético (catexia) dos elementos que estruturam o aparelho deve ser novamente liquidada, por um escoamento tendente à descarga, reconduzindo ao equilíbrio pelo alívio da tensão, e à reposição da quantidade em seu nível médio constante.

O aparelho funciona, pois, de acordo com um princípio de constância ou inércia da vida, em geral, e do psiquismo, em particular. As cargas de energia nervosa acorrentes nos elementos do sistema psíquico devem ser recebidas e processadas, distribuídas em feixes de ligações (ramificações), e canalizadas em ductos (trilhamentos/Bahnungen) que conduzem tais quantidades das extremidades nervosas aferentes às extremidades nervosas motoras, por meio das quais se realiza a descarga, com vistas à produção de uma experiência de satisfação. Esta função atende, dessa maneira, a exigências orgânicas que são necessidades, carências, empenhos, aspirações, desejos, enfim, atos volitivos, acompanhados de afetos e representados no psiquismo pelos impulsos ou pulsões.

Estas fazem parte, portanto, com complexo sistema por meio do qual o organismo realiza uma função vital essencial: aquela mesma que é enunciada no princípio de constância por Fechner, com o auxílio do qual Freud se esforça por compreender o princípio do prazer/desprazer como chave de inteligibilidade dos processos psíquicos. Manter constante o nível de energia nervosa no interior do aparelho, ou mesmo eliminar totalmente as tensões internas do organismo, bem como aquelas decorrentes de seu metabolismo com o meio ambiente, esta seria a função mais originária do psiquismo, da qual a obtenção do prazer e a evitação do desprazer seriam uma tendência. Se inicialmente Freud é levado a associar todo aumento quantitativo da massa de excitação acima de um determinado nível com a expressão qualitativa desse incremento como sentimento de desprazer, e sua descarga (portanto, rebaixamento quantitativo da massa de excitação) com a vivência afetiva de prazer (satisfação).

Como se recordará, nós tínhamos compreendido o princípio que domina todos os processos psíquicos como um caso especial da tendência à estabilidade fechneriana, e com isso atribuído ao aparelho psíquico a finalidade de eliminar inteiramente (zu nichts machen) a soma de excitação nele acorrente, ou pelo menos mantê-la no nível mais baixo possível. Barbara Low sugeriu para este suposto empenho o nome de princípio de nirvana, que nós aceitamos. Nós, porém, sem suficiente reflexão (unbedenklich), identificamos o princípio do prazer/desprazer com esse princípio de nirvana. Todo desprazer, portanto, teria de coincidir com uma elevação, todo prazer com um rebaixamento da tensão excitatória (Reizspannung) existente no psiquismo (im Seelischen), o princípio de nirvana (e o princípio do prazer, com ele supostamente idêntico) estaria 
inteiramente a serviço das pulsões de morte, cuja meta é a condução da vida em seu estado mais baixo à estabilidade do estado inorgânico ${ }^{5}$.

É sabido que este esquema teve de complexificar-se ao longo do desenvolvimento da obra freudiana, sendo objeto de um importante conjunto de modificações, mas não se pode afirmar que tenha sido completamente abandonado. E, de todo modo, é o esquema mobilizado por Freud em Além do Princípio do Prazer, como se pode depreender de seu importante e complexo capítulo final:

A ligação é um ato preparatório, que introduz e assegura o domínio do princípio do prazer. Separemos uma da outra função e tendência de modo mais incisivo do que o fizemos anteriormente. O princípio do prazer é então uma tendência, que está posta a serviço de uma função à qual compete tornar o aparelho psíquico livre de tensão em geral (überhaupt erregungslos), ou manter constante o montante (Betrag) de excitação nele existente, ou tão baixo quanto possível. Ainda não podemos nos decidir seguramente por nenhuma dessas concepções, mas notamos que a função assim determinada teria parte no mais universal esforço de todo ser vivo, de retornar ao estado inorgânico 6 .

Ora, a explicitação do caráter regressivo das pulsões dá ensejo à suspeita de que sua meta, como energia, não é a vida, mas o retorno ao inorgânico. Desse modo, a especulação sobre as origens tanto do psiquismo como da vida orgânica, em geral - despertada pelos fenômenos de repetição compulsiva observados na prática clínica - traz à tona um resultado teórico paradoxal: se as pulsões são a inscrição indelével da história de desenvolvimento da vida orgânica, o registro das etapas a que a matéria viva teria de regressar, para atingir sua meta final de repouso no inorgânico, isto significa, então, que a vida, em sua totalidade, engendra-se, estrutura-se e organiza-se a partir de um princípio contraditório.

Seu modo de funcionamento é, portanto, ontologicamente dialético: no interior da própria vida existem e atuam elementos pulsionais empenhados em torná-la inteiramente livres de excitação, ou seja, de eliminar as tensões internas e externas que são, no entanto, constitutivas do surgimento e desenvolvimento da vida. Tudo se passa, portanto, de tal modo que a vida abriga em seu âmago tanto as forças que a mobilizam no sentido ativo da compexificação, do desenvolvimento por agregação de unidades cada mais maiores eroticamente ligadas, como também de 'demoníacas' potências regressivas, desagregadoras, cujo principal empenho é fazer com que os organismos sejam levados à morte por motivos internos, por falecimento próprio, como resultado de insuficiências na eliminação dos produtos de seu próprio metabolismo. As pulsões seriam, então, como que

\footnotetext{
${ }^{5}$ FREUD, Das ökonomische Problem des Masochismus, p. 344s

${ }^{6}$ FREUD, Jenseits des Lustprinzips, p. 270
} 
satélites da morte, filogenéticas marcas mnêmicas de duplo sentido: indicadoras tanto do caminho percorrido pela vida orgânica ao longo de sua história evolutiva ascendente, quanto da tração que a impele para o retorno ao inorgânico; as pulsões seriam os marcos miliários do trajeto de forças que - do interior do próprio organismo - o constrangem a empenhar-se em morrer a própria morte.

Ora, esta especulação sobre a gênese e desenvolvimento da vida orgânica dá plausibilidade a uma hipótese filosófica sobre a natureza ontológica isonomicamente originária das pulsões de vida e de morte, que, por sua vez, torna imprescindível um esclarecimento maior e melhor a respeito da oposição entre vida e morte. "Se não quisermos abandonar a hipótese de pulsões de morte, temos de, desde o princípio (von allem Anfang an) associar a elas a pulsões de vida"7.

Para tanto, Freud considera necessário convocar os recursos da ciência biológica, para verificar se, com base nos mesmos, sua especulação metapsicológica não poderia ser cientificamente desautorizada. A tese a respeito das pulsões como expressão da inércia da vida orgânica exige a admissão de que o surgimento da vida - com a animação do inorgânico - seria evolucionariamente posterior à existência da matéria inorgânica, e que a primeira pulsão seria hipoteticamente um impulso visando retornar ao estado inorgânico, pela eliminação das tensões eletroquímicas que produziram, a partir da animação do inorgânico, a substância viva originária

No capítulo VI de Além do Princípio do Prazer Freud recorre, então, a teorias biológicas, para reforçar suas especulações, e depara-se, a esse respeito, com uma dificuldade incontornável, pois a própria biologia conhece com segurança muito pouco a respeito da morte, e não dispõe de uma teoria cientificamente confiável a respeito de seu estatuto ontológico, do momento de seu surgimento na história dos organismos. O percurso da argumentação de Freud vai remover a possibilidade de algum veto científico de suas hipóteses de parte da ciência biológica, razão pela qual considera-se autorizado a postular, ainda que como recurso heurístico condicional, um caráter originário para as pulsões de morte, situando-as necessariamente no mesmo plano ontológico das pulsões de vida.

Esta postulação desdobra-se na necessidade de promover um recuo que leva da teoria sobre a formação do aparelho psíquico a hipóteses sobre os primórdios do surgimento da vida, inclusive sobre a passagem do inorgânico à primitiva substância orgânica. Nesse contexto, fenômenos biológicos como migração das aves, a piracema, as fases de desenvolvimento constatáveis pela embriologia oferecem elementos que dão sustentação à hipótese de que existe um elemento regressivo no próprio núcleo dos fenômenos vitais, um impulso irrefreável, inerente aos processos de geração e reprodução,

${ }^{7}$ FREUD, Jenseits des Lustprinzips, p. 265s 
para retornar a um estado anterior de coisas que a matéria orgânica teve de abandonar, portanto para repetir e reproduzir.

Uma vez constatada esta natureza essencialmente regressiva e compulsória de toda pulsão - o Pulsional mostrando-se como regressão a um estado anterior do desenvolvimento do organismo -, então esta derivação metapsicológica reforça a convicção a respeito da existência e atuação de um elemento ainda mais primitivo e originário que o domínio do princípio do prazer/desprazer como dispositivo de constituição e funcionamento do aparelho psíquico. Na economia do argumento, que se constrói na busca de uma propriedade a cada vez mais originária da vida e da morte, Freud reconstitui criticamente um argumento de Weismann sobre a natureza não originária da morte, sua emergência como fenômeno característico da vida de organismos pluricelulares:

Esta morte dos seres vivos superiores é, com efeito, uma morte natural, uma morte a partir de causas internas, mas ela não se baseia (beruht) numa propriedade originária da substância viva (Ureigenschaft der lebenden Substanz), não podendo ser compreendida como uma necessidade absoluta, fundada na essência da vida. Ao invés disso, a morte é um dispositivo finalístico, um fenômeno (Erscheinung) de adaptação às condições externas de vida, pois desde a separação das células corporais em soma e plasma germinativo a duração ilimitada do indivíduo teria se tornado um luxo totalmente desprovido de finalidade. Com o surgimento desta diferenciação nos multicelulares, a morte tornou-se possível e conforme a fins. Desde então, morre o soma dos seres vivos superiores a partir de razões internas, em tempos determinados, os protozoários, porém, permaneceram imortais ${ }^{8}$.

Percebe-se que a teoria de Weismann a respeito da imortalidade dos protozuários não é congruente com a hipótese metapsicológica que Freud procura fundamentar: a saber, o caráter ontologicamente originário da morte. De acordo com a exigência teórica de Freud, a morte também teria de ser concebida efetivamente como 'uma propriedade originária da substância viva (Ureigenschaft der lebenden Substanz), uma necessidade absoluta, fundada na essência da vida'. A possibilidade de existência de tendências psíquicas ainda mais primitivas do que o princípio do prazer, vinda à tona a partir da análise dos fenômenos de repetição, bem como aquela derivada da natureza regressiva e conservadora de toda pulsão - a saber, no limite, uma tendência ínsita à vida, expressa pelo Pulsional, impelindo em direção da morte, da inércia primordial, do retorno ao inorgânico - proporcionam um reforço e uma justificação plausível para a referida hipótese metafísica metapsicológica de Freud.

$\mathrm{Na}$ ponderação das consequências da teoria biológica sustentada por Weismann, que afirma a pretensa imortalidade dos organismos multicelulares, Freud procura

${ }^{8}$ FREUD, Jenseits des Lustprinzips, p. 255s 
consolidar suas próprias posições teóricas a partir de experimentos também levados a efeito no campo da biologia. Com esse propósito, escreve Freud:

Com efeito, ouvimos dizer que as observações dos biólogos nos autorizam a hipótese de processos internos desse tipo, que conduzem à morte, também para os protistas. Porém, mesmo que estes se demonstrem como imortais, no sentido de Weismann, mesmo assim a assertiva deste, de que a morte seria uma aquisição tardia, vale apenas para as expressões manifestas da morte, e não torna impossível nenhuma hipótese sobre processos que impelem para a morte. Nossa expectativa, de que a biologia liquidaria plenamente o reconhecimento de pulsões de morte não se realizou'.

Podemos prosseguir nos ocupando com sua possibilidade, se além disso encontramos razões para isso. A notável semelhança da distinção weismanniana entre soma e plasma germinativo com nossa separação das pulsões de morte das pulsões de vida persiste, no entanto, e adquire novamente seu valor.

Como resultado do longo excurso pela biologia realizado em Além do Princípio do Prazer, temos, então que: em primeiro lugar, a metapsicologia conquistou um direito a prosseguir se ocupando com o reconhecimento de pulsões de morte como uma propriedade originária da substância orgânica. Em segundo lugar, uma notável semelhança pode ser teoricamente aproveitada: a distinção feita por Weismann entre soma e plasma germinativo não somente não põe fora de circulação a hipótese sobre o caráter originário da morte, como também serve de base para uma analogia entre outros dois pares de opostos: a diferenciação entre plasma germinativo e soma pode ser posta em correspondência com a distinção e oposição freudiana entre pulsões de vida e pulsões de morte.

É necessário, de todo modo, evitar a simplificação e superficialização decorrente dos 'ismos' em geral, quando se reconhece o 'dualismo pulsional' de Freud. Assim é que este dualismo não entra, de modo algum, em contradição alguma com a unidade do princípio prazer/desprazer - sustentada expressamente nas Formulações sobre os Dois Princípios das Ocorrências Psicológicas de 1911, e portanto, não derroga as teses sustentadas neste trabalho. Contudo, Além do Princípio do Prazer mantém resolutamente o dualismo pulsional como cerne da teoria metapsicológica. Este peso teórico, ou lastro metafísico do dualismo pulsional, tal como consistentemente sustentado por Freud, é uma consequência necessária da natureza regressiva da pulsão em geral, de sua concepção como elasticidade orgânica.

É com base nesses elementos que Freud confronta com vigor a hipótese monista de Carl Gustav Jung, para a qual toda energia pulsional é sinônima de libido. Freud não se furta à confrontação - ao contrário, faz questão de retomá-la explicitamente na segunda

${ }^{9}$ FREUD, Jenseits des Lustprinzips, p. 258 
edição de Além do Princípio do Prazer, publicada em 1921 - numa passagem decisiva do capitulo VI:

Nossa concepção foi, desde o início, uma dualista, e ela o é hoje mais incisivamente do que antes, desde que designamos os opostos não mais como pulsões sexuais e pulsões do Ego, mas pulsões de vida e pulsões de morte. A teoria da libido de Jung é, contrariamente a isto, uma teoria monista; que ele tenha denominado Libido sua única força pulsional, isso teve de gerar confusão, não deve, porém, nos influenciar doravante ${ }^{10}$.

Posição dualista que é sustentada também nos Abriss der Psychoanalyse:

Depois de longa refreamento e hesitação, nós nos decidimos a admitir apenas duas pulsões fundamentais, Eros e a pulsão de destruição. (A oposição entre pulsões de auto conservação e conservação da espécie, assim como aquela outra, entre pulsões do Ego e pulsões de objeto, permanece ainda no interior de Eros). A meta das primeiras é produzir unidades sempre maiores e mantê-las assim, portanto, ligação; a meta das outras é, inversamente, dissolver conexões, e assim destruir as coisas. No caso da pulsão de destruição, podemos pensar em que aparece como sua meta última transpor o vivente no estado inorgânico. Por isso, nós o denominamos também pulsão de morte. Se admitimos que o vivente adveio mais tardiamente do que o não-vivente, e é proveniente deste, então a pulsão de vida insere-se na mencionada fórmula segundo a qual uma pulsão almeja o retorno a um estado anterior ${ }^{11}$.

Hesitações e oscilações marcaram, pois, o desenvolvimento que culmina em Além do Princípio do Prazer, cujos elementos perduram até o final da vida de Freud. O dualismo pulsional é mantido, mesmo em face das dificuldades que o autor é obrigado a enfrentar em termos de sua comprovação empírica - sobretudo aquelas concernentes à demonstração da existência de pulsões de morte. É neste contexto que as conquistas teóricas resultantes dos estudos e trabalhos sobre o narcisismo desdobram-se na tarefa de revisão da teoria das pulsões sustentada por Freud antes de tais estudos. Desenvolvimento que o obriga a abandonar a oposição - anteriormente mantida - entre pulsões sexuais e pulsões do eu, reformulando-a para a oposição entre pulsões de vida e pulsões de morte, de modo tal que as pulsões do eu, em considerável medida, passam a ser incluídas entre as pulsões eróticas.

Eros é, então, o símbolo da libido, sendo esta a energia pulsional responsável pelas tarefas e esforços de ligação, cuja finalidade consiste na formação e manutenção de unidades sempre maiores e mais complexas, eroticamente ligadas. Eros - e a libido como energia das pulsões de vida - compreende, então as pulsões sexuais stricto sensu, toda a

\footnotetext{
${ }^{10}$ FREUD, Jenseits des Lustprinzips, p. 262

${ }^{11}$ FREUD, Entwurf einer Psychologie, p. 70-71
} 
gama das pulsões de natureza propriamente sexual, e não apenas a sexualidade a serviço da reprodução da espécie, concentrada nos órgãos genitais; os impulsos de auto conservação e outras pulsões do Ego, cuja energia é denominada libido, com finalidade de agregação. A esse conjunto opõem-se as pulsões destrutivas e agressivas - o conjunto das pulsões de morte [Destruktionstriebe] também incluídas no Ego -, cuja finalidade é a desagregação, a destruição das unidades vivas, com vistas finalmente ao regresso da substância viva ao repouso do inorgânico.

Persiste, ao longo de todo Além do Princípio do Prazer, uma dificuldade insuperável: a impossibilidade de indicar um representante direto das pulsões de morte, em estado puro, sem mistura com as pulsões eróticas. A esse respeito, Freud depara-se, com uma tarefa que de modo algum pode ser contornada: indicar uma representação das pulsões de morte, cuja existência e princípio de atuação foram teoricamente legitimados:

Não obstante, se a pulsão de morte deve poder afirmar-se como conceito, é preciso que dê provas de seu valor heurístico, servindo como princípio para interpretar ao menos uma parte dos fenômenos que caem sob o olhar da psicanálise. É por esta razão que Freud se vê na contingência de buscar um exemplo - não uma confirmação - da atividade da pulsão de morte ${ }^{12}$.

Freud recorre, então, ao conceito de fusão pulsional, argumentando que os representantes das pulsões de morte se mostrariam sempre fundidos ou coligados, de modo mais ou menos pronunciado, com pulsões eróticas. Os fenômenos do sadismo e do masoquismo, tornados compreensíveis a partir dos resultados dos trabalhos a respeito do narcisismo oferecem alguma indicação, ou plausibilidade para a designação de representantes de impulsos hostis, cuja atuação pode voltar-se tanto para o próprio Ego como para o exterior deste.

Com o recurso a tais fenômenos - de que a prática clínica e a vida cotidiana têm farta experiência - Freud pode indicar, ao menos indiretamente, com recurso ao conceito de fusão/disfusão pulsional, como as pulsões podem tomar o Ego como seu objeto, ligar-se a ele, desligar-se dele, retornar a ele, deslocando-se para outros objetos, e isso não somente com finalidades eróticas, mas também destrutivas. Uma fusão tão elementar e originária a ponto de fazer coincidir as duas correntes impulsivas fundamentais, ao longo de toda a vida sexual da pessoa - desde a fase oral, na qual a ligação erótica coincide com a destruição do objeto, até a fase da sexualidade genital, na qual as pulsões agressivas são um componente indispensável para uma vida sexual satisfatória.

Não apenas no sadismo e no masoquismo, enquanto formações patológicas da psique individual, mas também no plano da sociedade e da história universal são reconhecíveis fenômenos de agressão brutal, crueldade e destrutividade - como guerras, os

\footnotetext{
${ }^{12}$ MEZAN, Freud: A Trama dos Conceitos, p, 262
} 
massacres, as torturas e perseguições, atrocidades de toda espécie - que dão sustentação à hipótese de uma pulsão originária de destruição como ínsita à natureza humana. Com isso, Freud obtém o desiderato de manter a teorização metapsicológia não distante da clínica e das possibilidades de observação empírica.

Persiste, no entanto, a dificuldade de apontar na psicologia individual um representante puro da pulsão de morte, dificuldade acrescida de outra, não menos relevante: é inegável que os impulsos eróticos investem sua energia libidinal na organização de unidades sempre mais amplas, numa trajetória que guarda semelhança com uma linha de evolução e aperfeiçoamento, distendida ao infinito. Ora, como conciliar esse traçado evolutivo com a tendência regressiva de toda pulsão? A especulação metapsicológica se coloca, pois, em presença de outro dilema: se os impulsos eróticos se esforçam para unir os homens em organizações de uma ordem sempre mais crescente, impelindo-os para frente no sentido da vida, como verdadeiras pulsões de vida - o que encontra atestação empírica -, como atribuir-lhes um caráter regressivo, essência do pulsional?

Qual seria o estado anterior da existência do organismo que as pulsões compreendidas no grupo dos impulsos de vida (ou sexuais) teriam por propósito restabelecer?

Todavia, sentimos sempre ainda como sensível incômodo de nosso curso de pensamento não podermos demonstrar para o impulso sexual aquele caráter de uma compulsão à repetição, que primeiramente nos conduziu detecção das pulsões de morte. O domínio dos processos de desenvolvimento embrionário é, com efeito, rico em tais fenômenos de repetição, as duas células germinativas da reprodução sexual e sua história de vida são, elas mesmas, apenas repetições dos inícios da vida orgânica; no entanto, o essencial nos processos levados a efeito pela pulsão sexual é decerto a coalescência de dois corpos celulares. Só por meio dela é assegurada a imortalidade da substância viva nos seres vivos superiores ${ }^{13}$.

É evidente, no entanto, que com tais argumentos não são suficientes para remover a dificuldade de mostrar como e em que as pulsões sexuais são regressivas, e, portanto, também elas - como o pulsional em geral - são forças a serviço da morte.

Em meio às contribuições colhidas junto à biologia, à antropologia, à filosofia, à literatura, à psicologia, a contribuição psicanalítica seria capaz de lançar um raio de luz nas trevas em que se debate a perplexidade teórica. Ora, é para esconjurar essa desorientação em meio à escuridão total que a especulação parte em busca de uma hipótese que, mesmo mítica, permitiria, depois de convenientemente iluminada pelo filtro da interpretação psicanalítica, prover uma explicação que permite cumprir uma das mais

${ }^{13}$ FREUD, Jenseits des Lustprinzips, p. 264s 
fundamentais condições a que se submete a investigação metapsicológica. Assim, metapsicologia se atreve a recorrer ao mito porque, fazendo-o, ela responde a uma condição incontornável que, uma vez satisfeita, supre e elo teórico faltante, e permite derivar geneticamente toda pulsão - inclusive as eróticas - de uma mesma origem: a necessidade de restauração de um estado anterior de coisas, atestando, pois, seu caráter compulsoriamente regressivo.

Apropriando-se do mito formulado por Platão no Banquete, sobre a unidade hermafrodita primeva de nossos corpos atuais, Freud o reporta esse mito a uma fonte cultural ainda mais remota e vetusta: Os Upanishades da literatura védica: de acordo com a versão platônica do mitologema, no princípio, nossos corpos eram formados por três sexos: masculino, feminino, e um terceiro, unindo os dois outros: o Masculino-Feminino (das Mannweibliche). Desde que Zeus os dividiu em duas partes, o todo essencial (das ganze Wesen) cortado em dois, separados e opostos, de modo que a nostalgia (die Sehnsucht) da unidade de origem impele as duas metades a se reunir, de modo que elas se abraçam com as mãos e se imbricam mutuamente, no anseio de refundir-se ${ }^{14}$. Com tais elementos, podese formular uma hipótese teórica de natureza pronunciadamente mítico-fantástica, mas que satisfaz uma exigência epistemológica fundamental: tornar possível, consistente e plausível o ordenamento integral da série dos fatos a explicar, com base num regime regrado de analogias.

Seguindo a indicação do filósofo-poeta, devemos ousar a hipótese de que a substância viva, por ocasião de sua animação, foi rompida em pequenas partículas, que desde então, por meio das pulsões sexuais, anseiam por sua reunião? Que essas pulsões, nas quais perdura a afinidade química da matéria inanimada, atravessando o reino dos protistas, paulatinamente superam as dificuldades que opõe a elas um meio ambiente carregado de estímulos perigosos para a vida, e que as compele à formação de uma camada cortical protetora? Que estes fragmentos estilhaçados de substância viva alcançaram desse modo a multicelularidade, e finalmente transpuseram para as células germinativas o impulso para a reunião na mais elevada concentração ${ }^{15}$

Nesse caso, também as pulsões eróticas, ou de vida, atestariam uma regressividade fundamental, com o que se completa o movimento de explicação: todas as pulsões têm em comum a mesma natureza e caráter, que, por sua vez estariam relacionados à função mais primitiva e fundamental da substância viva, a saber, o retorno ao repouso do inorgânico (princípio de Nirvana). A experiência comum atesta que o maior prazer que somos capazes de atingir, aquele resultante da satisfação sexual, está indissociavelmente ligado a uma

\footnotetext{
${ }^{14}$ Cf. FREUD, Jenseits des Lustprinzips, p. 266

${ }^{15}$ FREUD, Jenseits des Lustprinzips, p. 267
} 
intensa descarga de energia psíquica que se aproxima de uma completa eliminação da tensão. Essa experiência, a que todos temos acesso, reforça a hipótese de acordo com a qual a ligação de uma quantidade de energia pulsional seria uma função preliminar, cuja finalidade consiste em preparar a quantidade de excitação para sua eliminação final ${ }^{16}$. Nesse caso, as pulsões eróticas, ou de vida, seriam, elas também, apenas desvios permanentes no caminho da morte.

No entanto, não há como negar que a atração entre os sexos, no exercício da função regressiva visando o retorno à perdida unidade primeva - e assim, encetando novamente o percurso em direção ao repouso no inorgânico - é também, ao mesmo tempo, a força que impele à obtenção do contrário dessa meta: a saber, a reprodução da divisão e do caminho que leva à formação dos complexos orgânicos cada vez maiores, cujo princípio está necessariamente dado com a fusão de duas células germinativas. Portanto, neste percurso desviante, atuaria um poderoso fator complicador, que mantém o destino final em perene suspensão: o retorno ao inorgânico não pode ser alcançado em virtude de um poderoso fator de complicação, a dialética que se institui entre sua meta e o caminho para atingi-la, contradição da qual resulta um permanente desvio em relação à referida meta.

Em todo caso, nós devemos nos dar conta de que o princípio de Nirvana pertencente à pulsão de morte, sofreu uma modificação no ser vivo através da qual se transformou em princípio do prazer, e nós evitaremos, de agora em diante, encarar os dois princípios como sendo um só. Não é difícil adivinhar de que poder esta modificação partiu, caso se queria, em geral, continuar com essa reflexão. Não pode ser senão da pulsão de vida, a libido, que, dessa maneira, adquiriu participação, ao lado da pulsão de morte, na regulação dos processos vitais. Nós obtemos assim uma curta, mas interessante, série de relações: o princípio de Nirvana representa a exigência da pulsão de morte; o princípio do prazer representa a reivindicação da libido e sua modificação, o princípio de realidade, a influência do mundo externo ${ }^{17}$.

A modificação do princípio do prazer a que Freud se refere no texto anteriormente citado já tinha sido minuciosamente examinada no texto do Projeto para uma Psicologia. Neste esboço de 1895, o problema tinha sido equacionado nos termos de maneira a considerar como a complexificação da vida orgânica teria determinado uma alteração da meta original visada pelo princípio do prazer, qual seja: a eliminação completa das tensões na recepção e processamento de energias nervosas pelo aparelho psíquico:

Só que o princípio de inércia é atravessado (durchbrochen) desde o princípio por uma outra relação. Com a complexidade interna, o sistema

\footnotetext{
${ }^{16}$ Cf. FREUD, Jenseits des Lustprinzips, p.264

${ }^{17}$ FREUD, Das ökonomische Problem des Masochismus, p.344
} 
neuronal recebe estímulos vindos do próprio elemento corporal, excitações endógenas, que, do mesmo modo, devem ser descarregadas. Estas são provenientes de células corporais, e geram as grandes necessidades, fome, respiração, sexualidade. Delas o organismo não pode subtrair-se, como das excitações externas; ele não pode empregar sua quantidade (Q) para a fuga do estímulo. Elas só cessam sob determinadas condições, que têm de ser realizadas no mundo externo, por exemplo, a necessidade de nutrição. Para realizar esta ação, que merece ser denominada específica, é necessário um esforço de realização (Leistung), que é independente, e em geral maior do que as quantidades endógenas (Qn), pois o indivíduo está sob condições que se pode designar como necessidade constringente (Not) da vida. Com isso, o sistema neuronal é obrigado a abandonar a tendência originária à inércia, isto é, ao nível $=0$. Ele tem de suportar um estoque de quantidade, para satisfazer as exigências desta ação específica ${ }^{18}$.

Ao interpretar esta decisiva modificação transformadora do princípio de nirvana em princípio do prazer e deste em princípio de realidade, levada a efeito sob a influência de pulsões de auto-conservação do Ego, Monzani lança luz sobre o papel fundamental da ligação nessa modificação, que inscreve no psiquismo o ponto de desvio que, por sua vez, torna permanentemente adiada e inatingível a meta final de retorno ao inorgânico:

[...] eis aqui, portanto, a passagem da pura tendência à ausência de tensão à manutenção de um estoque mínimo de energia, operado simultaneamente pela intromissão da pulsão ao nível do aparelho psíquico - a necessidade de manutenção de um nível mínimo e a Bindung operando nesse sentido ${ }^{19}$.

Desse modo, a morte final é inatingível porque no caminho para ela implantou-se, sob a regência de Eros, um desvio permanente:

Quando, enfim, a potência da morte é reconhecida explicitamente, quando enfim essa imantação radical é desvelada, essa atração irresistível para o vazio, para a não-excitação absoluta, é nomeada, nesse instante um outro pólo adquirirá uma força inusitada: a vida. A junção das pulsões sexuais e das pulsões de auto conservação - Eros - vai adquirir a propriedade inquietante de ser perturbadora da ordem gélida do inorgânico. Essas 'tensões' são a condição do vital desde o seu aparecimento e são exatamente elas que a pulsão de morte visa anular ${ }^{20}$.

\footnotetext{
${ }^{18}$ FREUD, Entwurf einer Psychologie, p. 306s

${ }^{19}$ MONZANI, Freud. O Movimento de Um Pensamento, p. 321

${ }^{20}$ MONZANI, Freud. O Movimento de Um Pensamento, p. 229
} 
Mesmo que tais resultados não sejam suficientes oferecer uma resposta exaustiva para as intrincadas questões pelas quais se desdobra a especulação metapsicológica de Freud, eles permitem, no entanto, articular e compreender o conjunto dos elementos implicados na montagem do problema, assim como levar a cabo uma tentativa plausível, teoricamente consistente, de solução do mesmo. Um resultado correspondente e análogo ao que Freud obtivera com a especulação teórica levada e efeito em Totem e Tabu.

A combinação (Zusammenhalten) da tradução psicanalítica do totem com o fato da refeição totêmica e com a hipótese darwiniana da horda primitiva permitiu em Totem e Tabu o surgimento de uma outra hipótese - ainda que fantástica em aparência -, mas que tornou possível um entendimento mais profundo de tais fenômenos, com um ganho adicional: produzir uma unidade insuspeitada entre séries de fenômenos até então isoladas, exibindo a origem comum do totemismo e da exogamia.

De modo que, se reunimos a interpretação psicanalítica do totem com o fato da refeição totêmica e com a hipótese darwiniana sobre o estado originário da sociedade humana, resulta daí a possibilidade de uma compreensão mais profunda, a perspectiva (der Ausblick) de uma hipótese que pode parecer fantástica, mas que oferece a vantagem de produzir uma insuspeitada unidade entre séries de fenômenos até então separados ${ }^{21}$.

Que em Além do Princípio do Prazer não se tenha encontrado um tipo de solução capaz de satisfazer integralmente os protocolos epistemológicos que pautam o modelo de ciência que Freud tinha em vista desde o Projeto de uma Psicologia Científica, isso talvez possa ser debitado à natureza do objeto, a carecer de remanejamentos teóricos constantes. Mesmo assim, essa restrição não afastaria a Psicanálise freudiana de um programa de pesquisa determinado com base em um ideal de ciência próprio de seu tempo, que descrê da onipotência, mas não dá suficiência persistente e sempre retificável da sabedoria do deus Logos.

Devemos estar prontos, também, para abandonar um caminho que estivemos seguindo por certo tempo, se parecer que ele não leva a qualquer bom fim. Somente os crentes, que exigem que a ciência seja um substituto para o catecismo que abandonaram, culparão um investigador por desenvolver ou mesmo transformar suas concepções. Podemos confortarnos também, pelos lentos avanços de nosso conhecimento científico, com as palavras do poeta: Was man nicht erfliegen kann, muss man erhinken. Die Schrift sagt, es ist keine Sünde zu hinken ${ }^{22}$.

\footnotetext{
${ }^{21}$ FREUD, Totem und Tabu, p. 425

${ }^{22}$ FREUD, Totem und Tabu, p. 272
} 


\section{Referências}

FREUD, S. Entwurf einer Psychologie. In: Aus den Anfängen der Psychoanalyse [18871902]. Frankfurt/M: Fischer Verlag, 1975.

FREUD, S. Jenseits des Lustprinzips. In: Freud, S. Studienausgabe. Band III. Psychologie des Unbewussten. Ed. A. Mitscherlich; A. Richard; J. Strachey. Frankfurt/M: Fischer Verlag, 1982a

FREUD, S. Totem und Tabu. In: Freud, S. Werke. Studienausgabe. Band IX: Fragen der Gesellschaft. Urprünge der Religion. Ed. A. Mitscherlich; A. Richard; J. Strachey. Frankfurt/M: Fischer Verlag, 1982b

FREUD, S. Das ökonomische Problem des Masochismus. In: Freud, S. Studienausgabe. Band III. Psychologie des Unbewussten. Ed. A. Mitscherlich; A. Richard; J. Strachey. Frankfurt/M: Fischer Verlag, 1982c

MEZAN, R. Freud: A Trama dos Conceitos, 3a. Ed, São Paulo: Ed. Perspectiva, 1991

MONZANI, L. R. Freud. O Movimento de Um Pensamento. Campinas: Editora da Unicamp, 1989 